\title{
Characterisation of anaemia and associated factors among infants and pre-schoolers from rural India
}

\author{
Krishnapillai Madhavan Nair ${ }^{1, *}$, Sylvia Fernandez-Rao ${ }^{2}$, Balakrishna Nagalla $^{3}$, \\ Radhakrishna Vijaya Kankipati ${ }^{4}$, Ravinder Punjal ${ }^{1}$, Little Flower Augustine ${ }^{1}$ \\ Kristen M Hurley ${ }^{5,6}$, Nicholas Tilton ${ }^{6}$, Kimberly B Harding ${ }^{7}$, Greg Reinhart ${ }^{8}$ and \\ Maureen M Black ${ }^{6}$
}

'Division of Micronutrient Research, National Institute of Nutrition, Indian Council of Medical Research, JamaiOsmania PO, Tarnaka, Hyderabad - 500 007, Telangana, India: ${ }^{2}$ Behavioural Sciences, National Institute of Nutrition, Indian Council of Medical Research, Hyderabad, Telangana, India: ${ }^{3}$ Biostatistics, National Institute of Nutrition, Indian Council of Medical Research, Hyderabad, Telangana, India: ${ }^{4}$ Clinical Studies, National Institute of Nutrition, Indian Council of Medical Research, Hyderabad, Telangana, India: ${ }^{5}$ Department of International Health, Johns Hopkins Bloomberg School of Public Health, Baltimore, MD, USA: ${ }^{6}$ Department of Pediatrics, University of Maryland School of Medicine, Baltimore, MD, USA: ${ }^{7}$ Micronutrient Initiative, Ottawa, Ontario, Canada:

${ }^{8}$ The Mathile Institute for the Advancement of Human Nutrition, Dayton, $\mathrm{OH}$, USA

Submitted 20 March 2015: Final revision received 6 May 2015: Accepted 28 May 2015: First published online 3 July 2015

\begin{abstract}
Objective: In India, national databases indicate anaemia prevalence of $80 \%$ among 6-35-month-old children and 58\% among 36-59-month-old children. The present study aimed to characterise anaemia and the associated factors among infants and pre-schoolers living in rural India.

Design: Multivariate logistic regression analysis of data collected prior to an intervention trial. Fe-deficiency with anaemia (IDA), Fe deficiency with no anaemia (IDNA) and anaemia without Fe deficiency were defined. Serum ferritin, soluble transferrin receptor (sTfR) and sTfR/log ferritin index were used to indicate Fe status.

Setting: Twenty-six villages of Nalgonda district, Telangana, India. Data were collected in community sites.

Participants: Four hundred and seventy-six infants (aged 6-12 months), 316 pre-schoolers (aged 29-56 months) and their mothers.

Results: Prevalence of anaemia among infants and pre-schoolers was 66.4 and $47.8 \%$, prevalence of IDA was $52 \cdot 2$ and $42 \cdot 1 \%$, prevalence of IDNA was $22 \cdot 2$ and $29.8 \%$, prevalence of anaemia without Fe deficiency was 14.2 and $5.7 \%$. Among infants, anaemia was positively associated with maternal anaemia $(\mathrm{OR}=3 \cdot 31 ; 95 \%$ CI $2 \cdot 10,5 \cdot 23 ; P<0 \cdot 001)$, and sTfR/log ferritin index (OR $=2 \cdot 21 ; 95 \%$ CI 1.39, 3.54; $P=0.001)$. Among pre-schoolers, anaemia was positively associated with maternal anaemia (OR $=3.77 ; 95 \%$ CI $1.94,7.30 ; P<0.001)$, sTfR/log ferritin index $(\mathrm{OR}=5.29 ; 95 \% \mathrm{CI} 2.67,10.50 ; P<0.001)$, high $\mathrm{C}$-reactive protein $(\mathrm{OR}=4.39$; $95 \%$ CI $1.91,10 \cdot 06, P<0 \cdot 001)$ and young age $(29-35$ months: OR $=1.92 ; 05 \% \mathrm{CI}$ $1 \cdot 18,3 \cdot 13, P=0 \cdot 009)$.

Conclusions: Anaemia prevalence continues to be high among infants and pre-schoolers in rural India. Based on STfR/ferritin index, Fe deficiency is a major factor associated with anaemia. Anaemia is also associated with inflammation among pre-schoolers and with maternal anaemia among infants and preschoolers, illustrating the importance of understanding the aetiology of anaemia in designing effective control strategies.
\end{abstract}

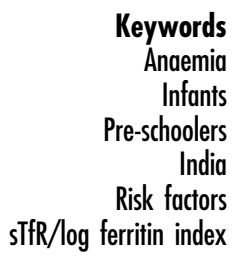
Infants India Risk factors sTfR/log ferritin index
Global estimates indicate that $43 \%$ of children under the age of 5 years suffer from anaemia ${ }^{(1)}$ and that about half of anaemia is caused by Fe deficiency. However, the prevalence and aetiology of anaemia are likely to be context-specific $^{(2)}$. Due to the high nutrient (e.g. dietary Fe) demands needed to support early physical growth, rapid brain development and early learning capacity, the infancy and pre-school periods are especially vulnerable 
to anaemia ${ }^{(3,4)}$. Anaemia and Fe deficiency are associated with perinatal mortality ${ }^{(5)}$, delayed child mental and physical development, negative behavioural consequences and reduced auditory and visual function ${ }^{(6,7)}$. Some of the consequences of early anaemia and Fe deficiency may be irreversible ${ }^{(8,9)}$.

In low- and middle-income countries, epidemiological evaluation is important in designing anaemia control programmes ${ }^{(10,11)}$. In India, national databases indicate an alarming anaemia prevalence of $80 \%$ among 6-35-month-old children and 58\% among 36-59-month-old children ${ }^{(12)}$. Although anaemia is considered to be multifactorial, most current strategies in India focus on increasing Fe intake because $\mathrm{Fe}$ is often a major cause of anaemia and there is insufficient evidence on other factors associated with anaemia among <5-year-old children. Multiple factors such as Fe deficiency, maternal $\mathrm{Hb}$ and food insecurity have been implicated in the aetiology of anaemia among children aged 12-24 months from Bangalore ${ }^{(13)}$. The present study aimed to characterise anaemia and assess the factors associated with anaemia among 6-12-month-old and 29-56 month-old-children, completing the spectrum and providing a holistic picture to formulate strategies aimed at anaemia prevention in children $<5$ years of age.

\section{Participants and methods}

\section{Study design, site and participants}

Project Grow Smart is a randomised controlled interventional trial, registered as NCT01660958. Details related to the development of the study design, study protocols, ascertainment of local approvals, and formative and pilot research are provided elsewhere ${ }^{(14)}$.

The study was conducted among infants and preschoolers in twenty-six villages of four state administrative blocks from Nalgonda district in the State of Telangana, which is the newest state of India, bifurcated from Andhra Pradesh. Infants and pre-schoolers with chronic morbidities, developmental delays, physical handicaps, or whose parents were planning to move out of the area within one year were excluded from the study. Children with severe anaemia $(\mathrm{Hb}<70 \mathrm{~g} / \mathrm{l})$ or severe stunting (length/height-for-age $Z$-score $\leq-3$ ) were not enrolled and were referred to the local hospital for evaluation and treatment, as indicated.

Recruitment for the infant phase was carried out by village-level workers, hired and trained as part of the study. The list of households in each village was procured from local social welfare workers (anganwadi workers). A door-to-door survey was carried out to identify households with infants aged 6-12 months. Of 551 infants in the designated age range, three were ineligible due to morbidity and developmental delay, twenty-one were not permanent residents and nine refused. Village-level workers enrolled the remaining 518 mothers and their infants after obtaining written consent. The pre-school phase was carried out by enrolling anganwadi centres (Indian public pre-schools set up under the government-sponsored national programme known as Integrated Child Development Services) serving more than fifteen children in the same villages where the infants were enrolled. Forty-six anganwadi centres were evaluated; nine did not meet enrolment criteria and we selected twenty-two through a randomisation procedure. Of the 336 eligible children based on age between 29 and 56 months, one refused, nine moved from the community or changed anganwadi centre. Three hundred and twenty-six pre-schoolers (aged 29-56 months) and their mothers were enrolled (Fig. 1) for the pre-school phase.

Infant data (socio-economic, maternal data, dietary diversity, morbidity) were collected through home visits followed by blood collection and anthropometry at a central community site within a time gap of one week. Medical records (mother-child immunisation card) were used to collect birth weight information. For pre-schoolers, all data, including blood samples, were collected at the anganwadi centre.

\section{Socio-economic variables}

Family ownership of twenty-seven items such as type of house, water source, type of fuel for cooking, electrification, furniture, vehicle for transport, telephone/mobile, expensive kitchen utensils, etc. were used for calculating the standard of living index (SLI). Weighted scores were based upon the relative significance of ownership of these items. The scores were classified as low (0-14), medium (15-24) and high $(\geq 25)$ standard of living ${ }^{(15)}$. Details of members in the family including their age, occupation, education and relationship to the primary caregiver were collected using a household roster and family size was obtained from this record.

\section{Anthropometric measurements}

Weight and length/height measurements followed a standard protocol ${ }^{(16)}$. Infants were weighed without diapers, pre-schoolers wore light clothing and mothers wore saris. The mother's weight was taken with and without the infant using a calibrated digital weighing scale to the nearest $0 \cdot 1 \mathrm{~kg}$ (Seca, Birmingham, UK). The difference was considered as infant weight. Weight of pre-schoolers and their mothers was recorded independently with the same scale. For infants, crown-to-heel length was measured to the nearest $0 \cdot 1 \mathrm{~cm}$ using an infantometer as has been described previously ${ }^{(16)}$. Both pre-schoolers' and maternal height was measured using a portable stadiometer to the nearest $0 \cdot 1 \mathrm{~cm}$ (Galaxy Scientific, New Delhi, India). Length/height measurements were conducted twice and repeated, if necessary, until at least two measurements agreed within $0.2 \mathrm{~cm}$. Child weight-for-length/height, weight-for-age and length/height-for-age $Z$-score values were calculated using the WHO growth standards ${ }^{(17)}$. 


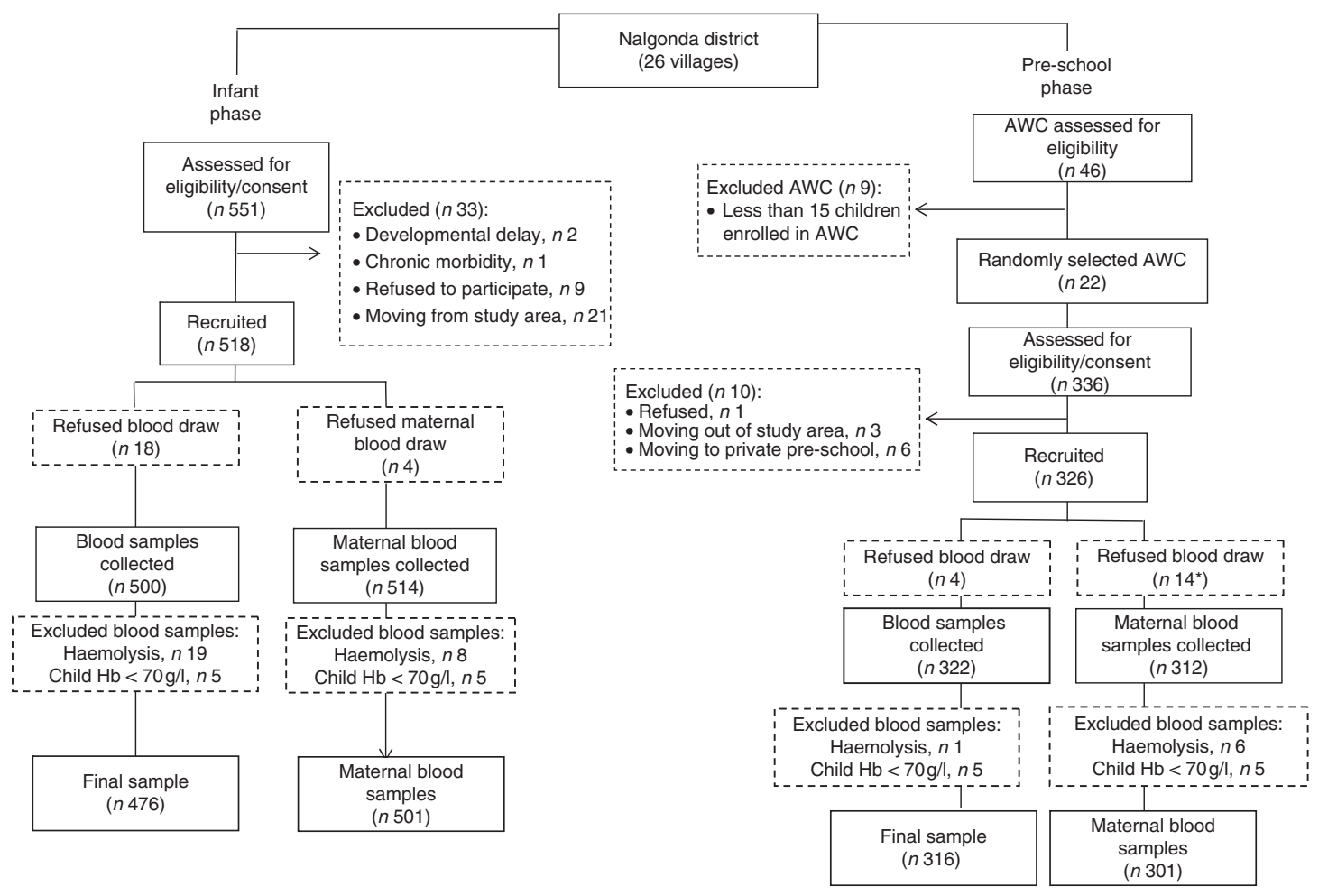

Fig. 1 Summary of the recruitment process (*employed women; AWC, anganwadi centre)

Stunting (low length/height-for-age), underweight (low weight-for-age) and wasting (low weight-for-length/ height) were defined as $Z$-scores $<-2$. Maternal BMI was calculated as [weight $(\mathrm{kg})] /[\text { height }(\mathrm{m})]^{2}$.

\section{Dietary diversity}

A child dietary diversity score (DDS) was calculated from an FFQ administered for the preceding week ${ }^{(18)}$. The twenty-seven food items were categorised into nine food groups: (i) cereals (one food); (ii) pulses (four foods); (iii) meat and meat products (four foods); (iv) eggs (one food); (v) milk products (two foods); (vi) green leafy vegetables and other vegetables (five foods); (vii) fruits (five foods); (viii) fortified foods and drinks (four foods); and (ix) fats (one food). For the pre-schoolers the DDS included sweet and salty snacks. Each food group was scored as ' 1 ' if there was consumption of at least one food item within that food group in the past week and a score of ' 0 ' if there was no consumption reported. The scores were averaged to arrive at a total DDS ranging from 0 to 9 for infants and from 0 to 11 for pre-schoolers. Higher scores represented higher dietary diversity and a median split was used to categorise data.

\section{Morbidity}

Information on child morbidity was collected through maternal recall of presence/absence of illness symptoms in the past $15 \mathrm{~d}$, including fever, vomiting, diarrhoea and cough accompanied by difficulty in breathing, experienced by the infant or pre-schooler ${ }^{(18)}$.

\section{Household food insecurity}

The Household Food Insecurity Access Scale (HFIAS) is a universal measure for the access component of household food insecurity ${ }^{(19)}$. The HFIAS is composed of a set of nine questions that have been used in several countries including India and distinguishes food-insecure from foodsecure households. Affirmation of any of the nine questions indicated household food insecurity.

\section{Laboratory analyses}

A $2 \mathrm{ml}$ non-fasting blood sample was collected from each infant, pre-schooler and mother between 10.00 and 12.00 hours from the antecubital vein into a heparinised Vacutainer by a trained phlebotomist. For infants and preschoolers, a numbing cream containing lidocaine and prilocaine (Neon Laboratories Limited, Mumbai, India) was applied to reduce discomfort. Blood collection from children who had acute morbidity was deferred until recovery. Blood was transported to the laboratory at the National Institute of Nutrition in Hyderabad, India in thermally insulated boxes containing ice packs; plasma was separated and stored in aliquots at $-20^{\circ} \mathrm{C}$ until analysis. The laboratory conducting the assays is under external quality assurance for ferritin and vitamin A estimations (VITAL-EQA programme; Centres for Disease 
Control and Prevention, Atlanta, GA, USA) and the analysis was carried out by technicians participating in this quality assurance programme.

$\mathrm{Hb}$ analysis was done in whole blood, on the same day of blood collection, using a commercial kit (HemoCor-D, Coral Systems; Tulip Group, Alto Santacruz, India). A sandwich ELISA was used to measure serum ferritin concentrations, as previously described ${ }^{(20,21)}$. The method was developed using a polyclonal antiserum raised in New Zealand white rabbit against purified human liver ferritin. A conjugate of the same IgG with horseradish peroxidase was prepared and used as an indicator antibody. The serum ferritin assay was standardised with purified human liver ferritin that was diluted to $1 \mu \mathrm{g} / \mathrm{ml}$ in buffered bovine serum albumin which was calibrated against International Standard 94/572 (National Institute for Biological Standards and Controls, South Mimms, UK). The assay sensitivity was $1 \mathrm{ng} / \mathrm{ml}$ and reported recoveries were above $90 \%$.

Soluble transferrin receptor (sTfR) was analysed using a sandwich ELISA kit with a minimum detectable dose of $0.5 \mathrm{nmol} / \mathrm{l}$ (R\&D Systems, Inc., Minnesota, MN, USA) and C-reactive protein (CRP) using a human CRP assay kit (Alpha Diagnostic International, San Antonio, TX, USA) with a minimum detectable limit of $10 \mathrm{ng} / \mathrm{ml}$ and assay range of $100-10000 \mathrm{ng} / \mathrm{ml}$.

Folate and vitamin $\mathrm{B}_{12}$ were analysed using a competitive protein-binding dual RIA kit (Siemens Medical Solutions Diagnostics, Los Angeles, CA, USA). The analytical sensitivity was $25 \cdot 1 \mathrm{pmol} / \mathrm{l}$ and $0.68 \mathrm{nmol} / \mathrm{l}$ for vitamin $\mathrm{B}_{12}$ and folate, respectively. Plasma $\mathrm{Zn}$ was analysed using atomic absorption spectrophotometry (AA7000 series; Shimadzu, Tokyo, Japan) by using flame atomic absorption with fetal bovine serum as external quality control ${ }^{(22)}$. All glass and plastic wares used for analysis of $\mathrm{Zn}$ followed standard protocols of washing using ultrapure water (Milli Q, Element; Millipore, Molsheim, France) and air dried. The assay sensitivity for $\mathrm{Zn}$ was $0.0153 \mu \mathrm{mol} / \mathrm{l}$. Folate and vitamin $\mathrm{B}_{12}$ deficiencies were defined as per the kit manufacturer's protocol as $<6.8 \mathrm{nmol} / 1$ and $<148$ pmol/1, respectively ${ }^{(23)}$. The cut-off for $\mathrm{Zn}$ deficiency was $<10 \mu \mathrm{mol} / \mathrm{l}^{(24)}$.

\section{Classification of Fe deficiency}

$\mathrm{Hb}$ cut-offs of $<110 \mathrm{~g} / \mathrm{l}$ and $<120 \mathrm{~g} / \mathrm{l}$ were used for anaemia among children (infants and pre-schoolers) and mothers, respectively. For mothers who were pregnant (5.3\% among mothers of infants and $8.2 \%$ among mothers of pre-schoolers), a cut-off of $<110 \mathrm{~g} / \mathrm{l}$ was used to define anaemia. For children, the cut-off used to grade severe anaemia was $<70 \mathrm{~g} / 1$, moderate anaemia was $70-<100 \mathrm{~g} / \mathrm{l}$ and mild anaemia was $100-<110 \mathrm{~g} / \mathrm{l}^{(25)}$. A ferritin cut-off of $<12 \mu \mathrm{g} / \mathrm{l}$ was used to indicate Fe deficiency ${ }^{(26)}$. The stricter criterion was used due to the additional marker employed, sTfR, which is relatively not affected by inflammation. The present data also showed no significant correlation between sTfR and CRP. CRP higher than $5 \mathrm{mg} / \mathrm{l}$ was considered indicative of current inflammation. There was a statistically significant but weak correlation between CRP and ferritin in infants $(r=0 \cdot 130, P=0.003)$, but not in pre-schoolers. For correction of inflammation-related elevation in ferritin concentrations, a factor of 0.67 was used with a corresponding CRP $>5 \mathrm{mg} / \mathrm{l}^{(27)}$.

In the absence of a universally accepted cut-off for sTfR, we plotted the frequency distribution of sTfR values of participants with no anaemia, no Fe deficiency and $\mathrm{CRP}<5 \mathrm{mg} / \mathrm{l}$ and the mean values were obtained and used as the cut-off ${ }^{(28)}$. The mean concentrations of plasma folate, vitamin $\mathrm{B}_{12}$ and $\mathrm{Zn}$ were above the respective cut-off values in this group. The ferritin concentrations were $\log$ transformed and sTfR/log ferritin index $(\mathrm{mg} / \mu \mathrm{g})$ values were computed in the same group as an indicator of Fe stores. Unlike pooled data, the sTfR concentrations in this group followed a normal distribution with mean concentrations of 2.54 (95\% CI $2.43,2.65) \mathrm{mg} / \mathrm{l}$ in infants ( $n$ 108) and 2.47 (95\% CI 2.34, 2.60) mg/l in pre-schoolers ( $n$ 103). A cut-off of $2.5 \mathrm{mg}$ was established and the mean $\mathrm{sTfR} / \log$ ferritin index of $1.9 \mathrm{mg} / \mu \mathrm{g}$ was used to categorise Fe deficiency where both biomarkers were not used independently (Table 1).

Based on the above cut-offs, children with normal concentrations of $\mathrm{Hb}$, ferritin and sTfR were considered as normal. Fe deficiency was defined as low ferritin and/or high sTfR regardless of anaemia status. Hb concentrations $\geq 110 \mathrm{~g} / \mathrm{l}$ with either low ferritin or high sTfR or both were

Table 1 Biomarkers of iron, other micronutrients and CRP among non-anaemic, non-iron-deficient infants (aged 6-12 months) and pre-schoolers (aged 29-56 months) with CRP $<5 \mathrm{mg} / \mathrm{l}$ for defining cut-off of sTfR, Nalgonda district, Telangana, India

\begin{tabular}{|c|c|c|c|c|c|c|}
\hline \multirow[b]{2}{*}{ Biomarker } & \multicolumn{3}{|c|}{ Infants } & \multicolumn{3}{|c|}{ Pre-schoolers } \\
\hline & $n$ & Mean & $95 \% \mathrm{Cl}$ & $n$ & Mean & $95 \% \mathrm{Cl}$ \\
\hline $\mathrm{Hb}(\mathrm{g} / \mathrm{l})$ & 108 & 118 & 117,120 & 103 & 121 & 120,122 \\
\hline Ferritin $(\mu \mathrm{g} / \mathrm{l})$ & 108 & $29 \cdot 4$ & $25 \cdot 7,33 \cdot 1$ & 103 & $26 \cdot 0$ & $21 \cdot 9,30 \cdot 2$ \\
\hline $\mathrm{sTfR}(\mathrm{mg} / \mathrm{l})$ & 108 & 2.54 & $2.43,2.65$ & 98 & 2.47 & $2.34,2.60$ \\
\hline $\mathrm{sTfR} / \mathrm{log}$ ferritin $(\mathrm{mg} / \mu \mathrm{g})$ & 108 & 1.86 & $1.76,1.96$ & 98 & 1.89 & $1.76,2.01$ \\
\hline $\mathrm{Zn}(\mu \mathrm{mol} / \mathrm{l})$ & 104 & $18 \cdot 6$ & $17 \cdot 5,19 \cdot 7$ & 101 & $13 \cdot 8$ & $13 \cdot 1,14 \cdot 6$ \\
\hline Folate $(\mathrm{nmol} / \mathrm{l})$ & 105 & $28 \cdot 3$ & $25 \cdot 8,30 \cdot 6$ & 103 & $13 \cdot 1$ & $12 \cdot 2,14 \cdot 0$ \\
\hline Vitamin $\mathrm{B}_{12}(\mathrm{pmol} / \mathrm{l})$ & 105 & 307 & 277,337 & 103 & 304 & 281,336 \\
\hline $\mathrm{CRP}(\mathrm{mg} / \mathrm{l})$ & 108 & 0.87 & $0.66,1.07$ & 100 & 0.96 & $0.74,1.17$ \\
\hline
\end{tabular}

CRP, C-reactive protein; sTfR, soluble transferrin receptor. 
considered as Fe deficiency with no anaemia (IDNA). Low $\mathrm{Hb}$ and either low ferritin or high sTfR or both were designated as having Fe-deficiency anaemia (IDA). Anaemia without Fe deficiency was defined as having low $\mathrm{Hb}$ with normal ferritin and sTfR concentrations.

\section{Statistical analyses}

We analysed the factors associated with anaemia in infants and pre-schoolers independently because the two samples differed in recruitment strategy, SLI and maternal education. The ferritin, sTfR and CRP concentrations were not normally distributed and were $\log$ transformed before analysis. Clustering effects in pre-school data were adjusted using mixed models for continuous variables and generalised estimating equations for categorical variables. We compared the mean values of micronutrient status among children with moderate, mild and no anaemia using ANOVA and post hoc least significant difference. For risk factors, a multivariate logistic regression model was built using social and biological variables, and odds ratios were calculated. The variables considered were household SLI, food insecurity, family size, maternal BMI, $\mathrm{Hb}$ and education; and child's age, birth weight, history of morbidity, CRP concentration, micronutrient status, stunting/wasting, DDS and sex. The biomarkers of micronutrient status considered were sTfR/log ferritin index and vitamin $\mathrm{B}_{12}$ concentrations. Zn deficiency was not considered in the case of infants and folate deficiency was not considered in either model based on low prevalence of deficiency. Separate models were built for ferritin and sTfR replacing sTfR/log ferritin index. Analyses were conducted using the statistical software package IBM SPSS Statistics version 19.0. $P<0.05$ was considered statistically significant.

\section{Results}

\section{Background characteristics}

We restricted our analysis to those with date in $\mathrm{Hb}$, which included 476 infants and 501 mothers; 316 pre-schoolers and 301 mothers. The discrepancies in numbers was due to difficulties encountered during blood collection from infants and some employed mothers being absent during blood collection for pre-schoolers. The sex ratio (female to male) was 0.8 in infants and 1.07 in pre-schoolers. The mean age of infants and pre-schoolers was 9.3 (SD 2.4) months and 37.2 (SD 6.3) months, respectively. Stunting occurred in $19.7 \%$ of infants and $40.5 \%$ of pre-schoolers, wasting in $9.8 \%$ of infants and $19.9 \%$ of pre-schoolers. The prevalence of low birth weight $(<2.5 \mathrm{~kg})$ was $16.0 \%$ among infants and $17.9 \%$ among pre-schoolers. An illness symptom in the past $15 \mathrm{~d}$ was reported in $48.0 \%$ of infants and $26.8 \%$ of pre-schoolers, with $16 \cdot 1 \%$ of infants and $10.9 \%$ of pre-schoolers having CRP $>5 \mathrm{mg} / \mathrm{l}$. Maternal secondary education (i.e. seventh grade and above) was
$75 \%$ in infants and $55 \%$ in pre-schoolers. Prevalence of maternal anaemia was $43.7 \%$ among mothers of infants and $34.2 \%$ among mothers of pre-schoolers. Three-quarters of infant households and $57 \%$ of pre-schooler households had SLI $\geq 25$ (Table 2 ), indicative of a high standard of living. Among infants, $12 \cdot 2 \%$ of households were food insecure and among pre-schoolers $14.2 \%$ of the households were food insecure.

\section{Description of anaemia and micronutrient status}

Anaemia was recorded in $66.4 \%$ of infants and $47.8 \%$ of pre-schoolers. Moderate anaemia occurred in $41.2 \%$ of infants and $24.1 \%$ of pre-schoolers. Mild anaemia occurred in approximately $25 \%$ of both groups (Table 3 ). There were five cases of severe anaemia in infants and five in pre-schoolers and did not form part of the analysis.

Infants suffered from deficiencies of $\mathrm{Fe}(30 \cdot 8 \%$ had low ferritin, $69.0 \%$ had high sTfR, 66.4\% had high sTfR/log ferritin index) and vitamin $\mathrm{B}_{12}(20 \cdot 6 \%)$. The deficiencies of $\mathrm{Zn}$ and folate were $<1 \%$. In pre-schoolers $44.9 \%$ had low ferritin, $66.9 \%$ had high sTfR, 33.1\% had high sTfR/log ferritin index, $10 \cdot 7 \%$ had low $\mathrm{Zn}, 4 \cdot 1$ and $5.4 \%$ suffered inadequacies of vitamin $\mathrm{B}_{12}$ and folate, respectively (Table 3).

Among children with anaemia, $78 \%$ of infants and $88 \%$ of pre-schoolers had concurrent Fe deficiency. Fe deficiency was about $70 \%$ in both groups of children. Fe deficiency without anaemia was found in $22.2 \%$ of infants and $29.8 \%$ of pre-schoolers, IDA in $52.2 \%$ and $42.1 \%$, respectively. There were $14.2 \%$ cases of IDNA in infants and $5.7 \%$ in pre-schoolers (Fig. 2). The sTfR/log ferritin index for normal children was 1.4 (95\% CI $1.35,1.51$ ) $\mathrm{mg} / \mu \mathrm{g}$ and $1.6(95 \% \mathrm{CI} 1.5,1.6) \mathrm{mg} / \mu \mathrm{g}$ for infants and pre-schoolers, respectively. The corresponding values for IDNA were $2 \cdot 6(95 \%$ CI $2 \cdot 4,2 \cdot 8) \mathrm{mg} / \mu \mathrm{g}$ and 3.1 (95\% CI $2 \cdot 9,3.4) \mathrm{mg} / \mu \mathrm{g}$, and for IDA were 3.7 (95\% CI 3.4, 4.0) $\mathrm{mg} / \mu \mathrm{g}$ and $4.8(95 \%$ CI $4.4,5 \cdot 1) \mathrm{mg} / \mu \mathrm{g}$, for infants and pre-schoolers, respectively. In anaemia without $\mathrm{Fe}$ deficiency, the ratio was $1.4(95 \%$ CI $1.35,1.5) \mathrm{mg} / \mu \mathrm{g}$ and $1.5(95 \%$ CI $1.3,1 \cdot 6) \mathrm{mg} / \mu \mathrm{g}$, respectively.

\section{Relationship between grades of anaemia and micronutrient status}

Infants with moderate anaemia had lower concentrations of vitamin $\mathrm{B}_{12}, \mathrm{Zn}$ and ferritin and higher sTfR and sTfR/log ferritin index in comparison to infants without anaemia. Pre-schoolers with moderate anaemia had a similar pattern, with lower concentrations of ferritin and folate, and higher sTfR and sTfR/log ferritin index, in comparison to pre-schoolers without anaemia. In both infants and pre-schoolers, moderate anaemia was associated with lower maternal $\mathrm{Hb}$, in comparison to children without anaemia (Table 4).

Infants with mild anaemia had lower concentrations of vitamin $\mathrm{B}_{12}$ than infants with no anaemia. Pre-schoolers with 
Table 2 Background characteristics of the participants: infants (aged 6-12 months), pre-schoolers (aged 29-56 months) and their mothers, Nalgonda district, Telangana, India

\begin{tabular}{|c|c|c|c|c|}
\hline \multirow[b]{2}{*}{ Variable } & \multicolumn{2}{|c|}{ Infants } & \multicolumn{2}{|c|}{ Pre-schoolers } \\
\hline & $n$ & $\%$ & $n$ & $\%$ \\
\hline \multicolumn{5}{|l|}{ Sex } \\
\hline Boys & 272 & $53 \cdot 1$ & 155 & $48 \cdot 3$ \\
\hline Girls & 240 & $46 \cdot 9$ & 166 & 51.7 \\
\hline \multicolumn{5}{|l|}{ Age (months) } \\
\hline $6-8$ & 222 & 43.4 & - & - \\
\hline $9-12$ & 290 & $56 \cdot 6$ & - & - \\
\hline $29-35$ & - & - & 145 & $45 \cdot 2$ \\
\hline $36-56$ & - & - & 176 & 54.8 \\
\hline \multicolumn{5}{|l|}{$Z$-score $<-2$} \\
\hline Weight-for-length/height & 50 & 9.8 & 64 & $19 \cdot 9$ \\
\hline Lemgth/height-for-age & 101 & $19 \cdot 7$ & 130 & 40.5 \\
\hline Weight-for-age & 97 & $19 \cdot 0$ & 148 & $46 \cdot 1$ \\
\hline Birth weight $<2.5 \mathrm{~kg}$ & 81 & $16 \cdot 0$ & 55 & $17 \cdot 9$ \\
\hline \multicolumn{5}{|l|}{ DDS $^{*}$} \\
\hline$\leq 3$ & 295 & 57.6 & - & - \\
\hline$\geq 4$ & 217 & $42 \cdot 4$ & - & - \\
\hline$\leq 7$ & - & - & 152 & $47 \cdot 7$ \\
\hline$\geq 8$ & - & - & 167 & 52.4 \\
\hline \multicolumn{5}{|l|}{ Morbidity } \\
\hline Any illness symptoms in past $15 \mathrm{~d} \dagger$ & 246 & 48.0 & 86 & $26 \cdot 8$ \\
\hline $\mathrm{CRP}>5 \mathrm{mg} / \mathrm{l}$ & 76 & $16 \cdot 1$ & 33 & 10.9 \\
\hline \multicolumn{5}{|l|}{ Maternal characteristics } \\
\hline \multicolumn{5}{|l|}{ Educational status } \\
\hline Illiterate & 80 & $15 \cdot 6$ & 88 & $27 \cdot 6$ \\
\hline Primary & 47 & $9 \cdot 2$ & 55 & $17 \cdot 2$ \\
\hline Secondary $\ddagger$ & 74 & 14.5 & 72 & $22 \cdot \overline{6}$ \\
\hline Higher & 311 & $60 \cdot 7$ & 104 & 32.6 \\
\hline Maternal anaemia§ & 219 & 43.7 & 103 & 34.2 \\
\hline \multicolumn{5}{|l|}{ SLI } \\
\hline $0-14$ & 12 & $2 \cdot 3$ & 12 & $3 \cdot 7$ \\
\hline $15-24$ & 110 & 21.5 & 126 & $39 \cdot 3$ \\
\hline$\geq 25$ & 390 & $76 \cdot 2$ & 183 & $57 \cdot 0$ \\
\hline Family size $>4$ & 104 & $20 \cdot 3$ & 58 & $18 \cdot 1$ \\
\hline \multirow[t]{2}{*}{ Household food insecurity } & 58 & $12 \cdot 2$ & 45 & $14 \cdot 2$ \\
\hline & $n$ & Mean or SD & $n$ & Mean or SD \\
\hline $\begin{array}{l}\text { Mean age (years) } \\
\text { SD }\end{array}$ & 501 & $\begin{array}{l}22 \cdot 9 \\
2 \cdot 89\end{array}$ & 319 & $\begin{array}{l}25 \cdot 0 \\
3 \cdot 27\end{array}$ \\
\hline
\end{tabular}

DDS, dietary diversity score; SLI, standard of living index.

The ' $n$ ' is after excluding cases with severe anaemia $(n 5)$ for both infants and pre-school children.

* $47.5 \%$ of infants and $88.2 \%$ pre-schoolers consumed fortified foods

†Fever was the most common symptom reported.

$\ddagger$ Seventh grade and above.

$\S \mathrm{Hb}<110 \mathrm{~g} / \mathrm{l}$ for pregnant mothers and $\mathrm{Hb}<120 \mathrm{~g} / \mathrm{l}$ for non-pregnant women.

Table 3 Percentage of infants (aged 6-12 months) and pre-schoolers (aged 29-56 months) with grades of anaemia and inadequate micronutrient status, Nalgonda district, Telangana, India

\begin{tabular}{|c|c|c|c|c|}
\hline \multirow[b]{2}{*}{ Variables } & \multicolumn{2}{|c|}{ Infants } & \multicolumn{2}{|c|}{ Pre-schoolers } \\
\hline & $n$ & $\%$ & $n$ & $\%$ \\
\hline Total anaemia $(\mathrm{Hb}=70-110 \mathrm{~g} / \mathrm{l})$ & 476 & $66 \cdot 4$ & 316 & 47.8 \\
\hline Moderate anaemia $(\mathrm{Hb}=70-100 \mathrm{~g} / \mathrm{l})$ & 196 & $41 \cdot 2$ & 76 & $24 \cdot 1$ \\
\hline Mild anaemia $(\mathrm{Hb}=100-110 \mathrm{~g} / \mathrm{l})$ & 120 & $25 \cdot 2$ & 75 & 23.7 \\
\hline No anaemia $(\mathrm{Hb}>110 \mathrm{~g} / \mathrm{l})$ & 160 & $33 \cdot 6$ & 165 & $52 \cdot 2$ \\
\hline Ferritin $<12 \mu \mathrm{g} / \mathrm{l}$ & 464 & $30 \cdot 8$ & 314 & 44.9 \\
\hline $\mathrm{sTfR}>2.5 \mathrm{mg} / \mathrm{l}$ & 473 & $69 \cdot 0$ & 299 & $66 \cdot 9$ \\
\hline $\mathrm{sTfR} / \mathrm{log}$ ferritin $>1.9 \mathrm{mg} / \mu \mathrm{g}$ & 464 & $66 \cdot 4$ & 299 & 33.1 \\
\hline Folate $<6.8 \mathrm{nmol} / \mathrm{l}$ & 466 & 0.9 & 314 & 4.1 \\
\hline Vitamin $B_{12}<148 \mathrm{pmol} / \mathrm{l}$ & 466 & $20 \cdot 6$ & 314 & 5.4 \\
\hline $\mathrm{Zn}<10.0 \mu \mathrm{mol} / \mathrm{l}$ & 458 & 0.9 & 307 & $10 \cdot 7$ \\
\hline
\end{tabular}

sTfR, soluble transferrin receptor.

Children with severe anaemia were excluded from analysis. 


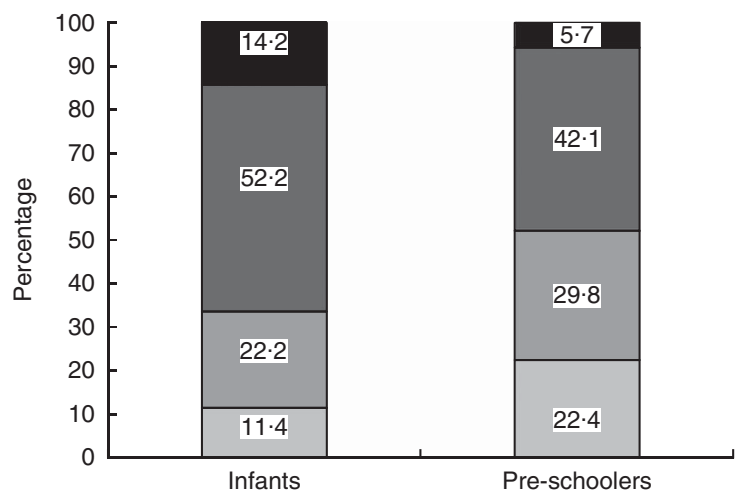

Fig. 2 Classification of iron deficiency among infants (aged 6-12 months) and pre-schoolers (aged 29-56 months), Nalgonda district, Telangana, India. $\square$, Normal $(\mathrm{Hb}>110 \mathrm{~g} / \mathrm{l}$, ferritin $>12 \mu \mathrm{g} / \mathrm{l}$ and soluble transferrin receptor $(\mathrm{sTfR})<2.5 \mathrm{mg} / \mathrm{l})$; $\square$, iron deficiency with no anaemia (IDNA; $\mathrm{Hb}>110 \mathrm{~g} / \mathrm{l}$, ferritin $<12 \mu \mathrm{g} / \mathrm{l}$ or $\mathrm{sTfR}>2.5 \mathrm{mg} / \mathrm{l}$ or both); $\square$, iron-deficiency anaemia (IDA; $\mathrm{Hb}<110 \mathrm{~g} / \mathrm{l}$, ferritin $<12 \mu \mathrm{g} / \mathrm{l}$ or $\mathrm{sTfR}>2.5 \mathrm{mg} / \mathrm{l}$ or both); , anaemia without iron deficiency $(\mathrm{Hb}<110 \mathrm{~g} / \mathrm{l}$, ferritin $>12 \mu \mathrm{g} / \mathrm{l}$ and $\mathrm{sTfR}<2.5 \mathrm{mg} / \mathrm{l})$

mild anaemia had higher sTfR and sTfR/log ferritin index and lower folate concentrations than pre-schoolers with no anaemia. In both infants and pre-schoolers, mild anaemia was associated with lower maternal $\mathrm{Hb}$ in comparison to children without anaemia. The mean concentrations of micronutrients and maternal $\mathrm{Hb}$ were not significantly different among children with mild and moderate anaemia except for a higher sTfR and sTfR/log ferritin index in moderate anaemia among both infants and pre-schoolers (Table 4).

\section{Logistic regression analyses of factors associated with anaemia}

Infants were more likely to have anaemia if they had high sTfR/log ferritin index or their mothers had anaemia. Pre-schoolers were more likely to have anaemia if they were younger, had elevated CRP or elevated sTfR/log ferritin index or if their mothers had anaemia. We also observed a trend $(P=0.095)$ in DDS of $\leq 3$ among anaemic infants (Table 5). Among the food groups, fortified foods alone showed an association with anaemia among infants (62.1\% anaemia in infants who received fortified foods compared with $70.0 \%$ anaemia in infants who did not receive fortified foods, $P=0.039$ ). A trend was also observed with respect to low birth weight $(P=0.068)$ among pre-schoolers. Ferritin tested separately in the same model showed significant risk among infants and preschoolers, while for sTfR the odds ratios were significant only for pre-schoolers.

\section{Discussion}

The current comprehensive study involving several biological and social variables characterised anaemia and

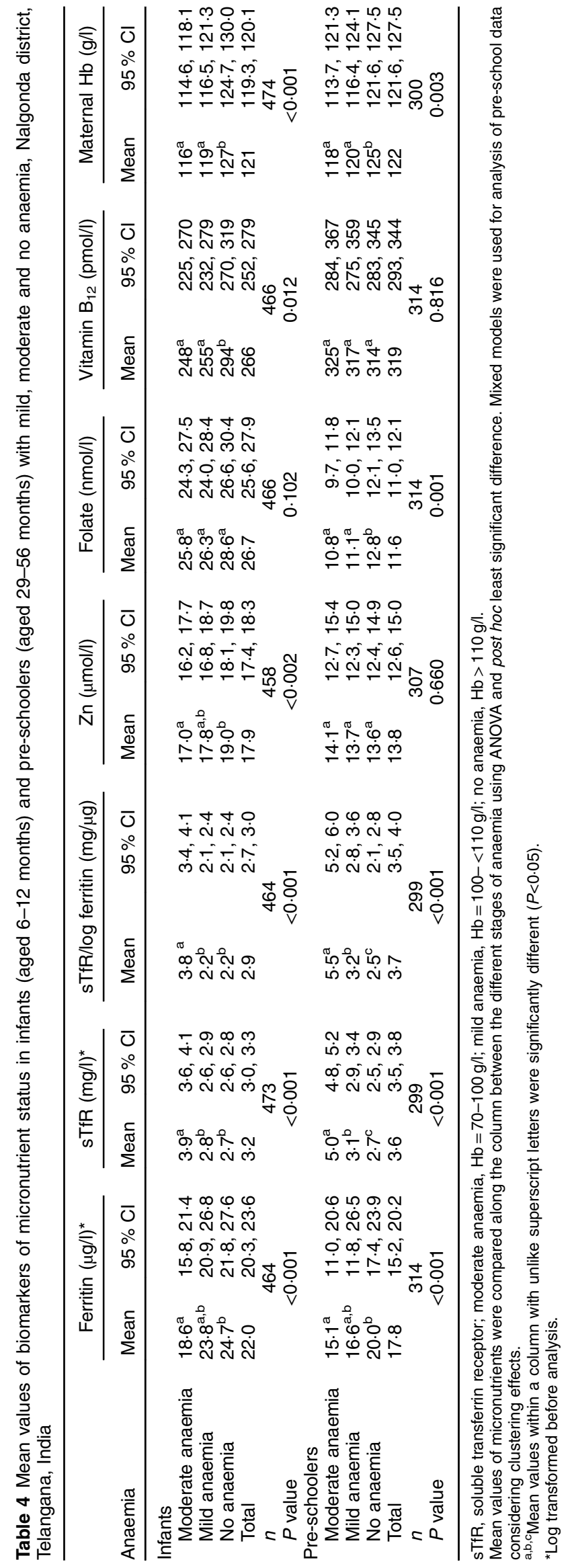


Table 5 Factors associated with anaemia among infants (aged 6-12 months) and pre-schoolers (aged 29-56 months), Nalgonda district, Telangana, India

\begin{tabular}{|c|c|c|c|c|c|c|c|}
\hline \multirow[b]{2}{*}{ Variable } & \multirow[b]{2}{*}{ Risk } & \multicolumn{3}{|c|}{ Infants ( $n$ 445) } & \multicolumn{3}{|c|}{ Pre-schoolers ( $n$ 263) } \\
\hline & & OR & $95 \% \mathrm{Cl}$ & $P$ & OR & $95 \% \mathrm{Cl}$ & $P$ \\
\hline \multicolumn{8}{|l|}{ Model 1} \\
\hline \multicolumn{8}{|l|}{ Child factors } \\
\hline Sex & Boy & 1.42 & $0.91,2.21$ & 0.126 & 1.20 & $0.69,2.11$ & 0.522 \\
\hline Age & $\begin{array}{l}\text { Infants (9-12 months), } \\
\text { pre-schoolers ( } 29-35 \text { months) }\end{array}$ & $1 \cdot 20$ & $0.73,1.96$ & 0.471 & 1.92 & $1 \cdot 18,3 \cdot 13$ & 0.009 \\
\hline Any illness symptoms in past $15 d$ & Yes & 0.89 & $0.57,1.38$ & 0.603 & 0.70 & $0.40,1.22$ & 0.208 \\
\hline $\mathrm{Zn}$ & $<10.0 \mu \mathrm{mol} / \$$ & - & - & - & 1.49 & $0.44,5.06$ & 0.525 \\
\hline CRP & $\geq 5 \mathrm{mg} / \mathrm{l}$ & 1.69 & $0.91,3.13$ & 0.095 & 4.39 & $1.91,10.06$ & $<0.001$ \\
\hline sTfR/log ferritin & $>1.9 \mathrm{mg} / \mathrm{ug}$ & 2.21 & $1.39,3.54$ & 0.001 & 5.29 & $2.67,10.50$ & $<0.001$ \\
\hline Vitamin $\mathrm{B}_{12}$ & $<148 \mathrm{pmol} / \mathrm{l}$ & 1.33 & $0.77,2.29$ & 0.313 & 0.95 & $0.30,3.06$ & 0.939 \\
\hline WAZ & $<-2$ & 0.93 & $0.50,1.75$ & 0.826 & 0.65 & $0.30,1.40$ & 0.270 \\
\hline HAZ & $<-2$ & 1.46 & $0.79,2.70$ & 0.231 & 1.29 & $0.63,2.62$ & 0.488 \\
\hline DDS & $\leq 3 / \leq 7 \S$ & 1.51 & $0.93,2.46$ & 0.095 & 1.13 & $0.56,2.27$ & 0.730 \\
\hline Birth weight & $<2.5 \mathrm{~kg}$ & 0.98 & $0.53,1.83$ & 0.954 & 1.94 & $0.95,3.96$ & 0.068 \\
\hline \multicolumn{8}{|l|}{ Maternal/social factors } \\
\hline SLI & $<24$ & 0.86 & $0.51,1.46$ & 0.584 & 1.02 & $0.66,1.56$ & 0.938 \\
\hline Maternal anaemia & $<120 \mathrm{~g} / \mathrm{ll|}$ & $3 \cdot 31$ & $2 \cdot 10,5 \cdot 23$ & $<0.001$ & 3.77 & $1.94,7.30$ & $<0.001$ \\
\hline Maternal BMI & $<18.5 \mathrm{~kg} / \mathrm{m}^{2}$ & 1.21 & $0.78,1.88$ & 0.403 & 0.88 & $0.47,1.64$ & 0.693 \\
\hline Maternal education & Illiterate and primary level education & 1.38 & $0.83,2.32$ & 0.217 & 1.90 & $0.88,4.09$ & 0.102 \\
\hline Family size & $>4$ & 0.74 & $0.44,1.26$ & 0.270 & 1.11 & $0.59,2.06$ & 0.752 \\
\hline \multirow{2}{*}{\multicolumn{8}{|c|}{ Model $2^{*}$}} \\
\hline & & & & & & & \\
\hline Ferritin & $<12 \mu \mathrm{g} / \mathrm{l}$ & 1.81 & $1.10,2.99$ & 0.020 & 3.13 & $1.73,5.65$ & $<0.001$ \\
\hline \multicolumn{8}{|l|}{ Model 3† } \\
\hline sTfR & $>2.5 \mathrm{mg} / \mathrm{l}$ & 1.54 & $0.97,2.45$ & 0.068 & 8.41 & $4.78,14.79$ & $<0.001$ \\
\hline
\end{tabular}

CRP, C-reactive protein; sTfR, soluble transferrin receptor; WAZ, weight-for-age Z-score; HAZ, length/height-for-age Z-score; DDS, dietary diversity score; $\mathrm{SLI}$, standard of living index.

*In model 2, sTfR/log ferritin replaced with ferritin.

†ln model 1, sTfR/log ferritin replaced with sTfR.

fLow prevalence of plasma $\mathrm{Zn}<10.0 \mu \mathrm{mol} / \mathrm{l}$ to include in the model to compute OR for infants.

$\S \leq 3 / \leq 7$ for infants and pre-schoolers, respectively. The results are based on logistic regression analysis. The analysis for pre-schoolers considered the cluster design.

$\| \mathrm{Hb}$ cut-off of $110 \mathrm{~g} / \mathrm{l}$ for pregnant women.

the factors associated with anaemia among infants and pre-schoolers in rural India. Anaemia continues to be a significant public health issue among young children in this setting. In addition to the child's $\mathrm{Fe}$ status and maternal anaemia, which were significantly associated with anaemia in infants and pre-schoolers, inflammation and younger age of the child were significantly associated with anaemia in pre-schoolers.

Rates of undernutrition among pre-schoolers were comparable with the national average for children $<5$ years of $48 \%$ stunting, $20 \%$ wasting and $43 \%$ underweight ${ }^{(12)}$. However, among infants, the prevalence rates appeared to be lower. The low rates of stunting may be due to the age-dependent sharp increase in stunting from 6 months onwards, peaking at 20 months and plateauing thereafter, as demonstrated in the same national survey. The lower prevalence of undernutrition may also be a reflection of comparatively higher household SLI and maternal education among infants in the present study.

We found that two-thirds of the infants and almost one-half of the pre-schoolers had anaemia, with a moderate anaemia prevalence of $41 \%$ and $24 \%$ in infants and pre-schoolers, respectively. These rates are consistent with national rates of anaemia among infants and pre-schoolers ${ }^{(1,12)}$ and with the prevalence of moderate anaemia $(>50 \%)$ in children less than 3 years old in other states of India ${ }^{(29)}$. Although programmes to control anaemia in low- and middle-income countries mostly concentrate on Fe deficiency as the major cause, in the presence of inflammation, defining Fe deficiency is difficult and therefore we used ferritin and sTfR along with $\mathrm{CRP}^{(10,30)}$. Serum ferritin reflects the storage Fe compartment and sTfR reflects the functional Fe compartment. Conceptually, sTfR/log ferritin ratio unifies the spectrum of deficiency and therefore is more attractive and useful in defining $\mathrm{Fe}$ deficiency ${ }^{(31)}$. Additionally it is difficult to characterise Fe deficiency in infants and pre-schoolers in settings where the target group suffers from widespread anaemia, with meagre opportunity for establishing adequate Fe stores and has a background of inflammation. Using receiver-operating characteristic curve analysis the sTfR/log ferritin index has shown to have excellent sensitivity and specificity in reflecting Fe depletion ${ }^{(31)}$. One meta-analysis also greatly supports this conclusion ${ }^{(32)}$. Therefore we used this index to draw conclusions.

Since information was not available on the sTfR cut-off and the sTfR/log ferritin index in this age group, we derived a cut-off value based on sTfR concentrations of 
non-anaemic, non-Fe-deficient children devoid of elevated $\mathrm{CRP}^{(33)}$. The distribution of sTfR in these children followed a normal distribution unlike in the total sample and therefore we used mean values of $2.5 \mathrm{mg} / \mathrm{l}$ for sTfR and $1.9 \mathrm{mg} / \mathrm{\mu g}$ for $\mathrm{sTfR} / \mathrm{log}$ ferritin index value for categorisation of deficient $v$. sufficient Fe stores. The derived cut-off of sTfR is in concordance with the reported cut-off value of $2.5 \mathrm{mg} / \mathrm{l}$ for adults ${ }^{(34)}$ while the $\mathrm{sTfR} / \mathrm{log}$ ferritin index was close $(1.8 \mathrm{mg} / \mu \mathrm{g})$ to that of adults ${ }^{(33)}$ and varied according to the classification of Fe deficiency. Accordingly, $66 \%$ of infants and $33 \%$ of pre-schoolers had deficient Fe stores. These findings compare with the high prevalence of $\mathrm{Fe}$ deficiency $(62 \%)$ reported in 12-23-month-old children from Bangalore, India ${ }^{(13)}$. In the present study, the logistic regression models also confirmed that Fe deficiency is the major contributor of anaemia in this setting as evidenced by a higher odds of anaemia in Fe deficiency in both infants (two times) and pre-schoolers (five times). The situation appears to be different with respect to subSaharan Africa, where anaemia of inflammation can be as important or more important than IDA ${ }^{(35)}$.

Maternal anaemia was also found to be strongly associated with anaemia in both infants and pre-schoolers. Globally, more than one-third of pregnant women suffer from anaemia ${ }^{(1)}$. Cross-sectional studies have reported associations of maternal anaemia with prematurity and low birth weight, lower socio-economic status, low breast milk nutrient content, inappropriate complementary feeding and low maternal nutritional knowledge ${ }^{(13,36)}$. The prospect of protecting infant and young child health through targeting maternal anaemia during pregnancy has been suggested ${ }^{(37)}$. The implications for child health and development with respect to an anaemic caregiver have also been recognised ${ }^{(38)}$. Therefore, prevention strategies should target adolescent girls and women of reproductive age to eliminate or reduce the burden of anaemia before entering into the higher nutritional demands of pregnancy ${ }^{(39-41)}$. A continuum in interventions is required during the reproductive period for the benefit to reach the offspring.

In this context, tackling anaemia through a life cycle approach, as recently introduced in India ${ }^{(42)}$, is supported by our findings. Multiple micronutrients with an emphasis on those which help in absorption and or mobilisation of $\mathrm{Fe}$ for $\mathrm{Hb}$ regeneration could be of better impact than Fe and folic acid alone. In view of the general lack of dietary diversity in the target group, point-of-use fortification with multiple micronutrients appears to be an attractive option. Systematic reviews have shown that home fortification of foods with multiple micronutrient powders is an effective intervention to reduce anaemia and Fe deficiency in children aged 6-23 months, with results comparable to the benefits of a daily $\mathrm{Fe}$ supplementation programme ${ }^{(43)}$. Activities to improve food security and dietary diversity are complementary to provision of $\mathrm{Fe}$, although they may be longer-term strategies. Currently, global nutrition efforts have a strong focus on the first $1000 \mathrm{~d}$ of life, and while this is a critical period for growth and development ${ }^{(39)}$, our findings also highlight that malnutrition continues to be a major issue in the pre-school years in this setting. Because anaemia and Fe deficiency are related to cognitive and socio-emotional development and learning ability beyond infancy, it is essential that control strategies also include the pre-school years.

Risks of anaemia are a complex interplay of political, ecological, social and biological factors, and not just Fe status. We found an increased risk of anaemia with CRP in pre-schoolers. A similar association was observed elsewhere in India ${ }^{(13)}$. About $6-14 \%$ of anaemia in this group was not associated with Fe status. It appears that inflammation is a significant factor for anaemia in preschoolers. However, in spite of higher prevalence of illness symptoms and higher CRP concentrations, this association was not observed in infants. The absence of a relationship with inflammation in infants may be due to a very high prevalence of IDA, thereby masking the association with inflammation. Inflammation-associated anaemia is generally due to the known pathway of hepcidin-induced regulation of Fe homoeostasis, preventing the entry of Fe into systemic circulation, creating a pseudo deficiency situation ${ }^{(44)}$. In the presence of inflammation coexistent with Fe deficiency, approaches targeting the root cause of inflammation also need to be identified and addressed.

The association between age and anaemia in preschoolers shows a decreasing severity of anaemia with higher age category. Risk factors such as low birth weight and dietary diversity showed a trend in these children. Food insecurity was not a significant factor associated with anaemia as the majority of households were food secure. The interdependence of variables studied could be one of the reasons for not observing them as risk factors for anaemia in the present study. A significant association has been shown elsewhere with respect to low birth weight, infection ${ }^{(45)}$, stunting, family income, maternal education $^{(46)}$, exclusive breast-feeding ${ }^{(47)}$ and $\mathrm{Hb}$ at 6 months ${ }^{(48)}$. In addition to these, factors such as more siblings, crowded living conditions, inappropriate complementary food introduction ${ }^{(49)}$, poorer sanitary conditions and being male have also been associated with anaemia ${ }^{(50)}$. Studies conducted in Bangalore, India have also shown factors such as Fe deficiency, maternal anaemia, sex, food insecurity and age to be associated with anaemia ${ }^{(13)}$.

Serum $\mathrm{Zn}$ indicated an adequate status which has limitations of having collected non-fasting blood samples from infants and pre-schoolers. However, there was an association with moderate anaemia in infants, suggesting a role of $\mathrm{Zn}$ deficiency in these children. Inadequacy of vitamin $B_{12}$ was about $20 \%$. Although not associated with anaemia in the model, the mean values of vitamin $B_{12}$ were significantly lower in infants with anaemia. Therefore the influence of multiple micronutrient deficiencies of vitamin $B_{12}$ and $Z n$ could not be ruled out. 
The major strength of our study is the simultaneous measurement of several social and biological variables including sTfR/log ferritin ratio. Knowing the factors associated with anaemia in a population should be informative to policy makers and those designing intervention studies. However, factors such as haemoglobinopathies and the roles of vitamin A deficiency and hookworm infestation were not studied. Due to logistic difficulties and budgetary constraints we could not assess factors such as haemoglobinopathies, vitamin A status and hookworm infestation, although they may also contribute to anaemia. However, at national level, India has a deworming programme and massive dose of vitamin A programme. Haemoglobinopathies are not known to be prevalent in this area and may not contribute significantly to anaemia in this region.

\section{Conclusion}

Anaemia prevalence was high among infants and preschoolers from rural India, indicating a problem of severe public health significance with Fe deficiency as the major contributor. The roles of maternal anaemia and inflammation, in addition to that of $\mathrm{Fe}$, in anaemia among infants and pre-schoolers are highlighted.

\section{Acknowledgements}

Acknowledgements: The authors acknowledge the initial conceptualisation and contributions of Dr Shahnaz Vazir PhD, Former Deputy Director and Emeritus Scientist, National Institute of Nutrition (ICMR) and Dr B. Sesikeran $\mathrm{MD}$, Former Director, National Institute of Nutrition (ICMR). They also acknowledge Mr K. Narasimha Reddy BSc, Technical Assistant, National Institute of Nutrition for assistance in collection of anthropometry data. Financial support: This work was supported by the Micronutrient Initiative, Ottawa, Canada and the Mathile Institute for the Advancement of Human Nutrition, Dayton, OH, USA. Conflict of interest: None declared. K.B.H. and G.R. are employees of the Micronutrient Initiative and the Mathile Institute for the Advancement of Human Nutrition, respectively. Authorship: M.M.B., K.M.N., S.F.-R., N.B., K.V.R. and K.M.H. conceptualised the study; S.F.-R., P.R. and N.T. acquired data; K.M.N. and L.A. drafted the manuscript; all authors have contributed to analysis and interpretation of data, critically reviewed the manuscript, read and approved the final manuscript. Ethics of human subject participation: This study was conducted according to the guidelines laid down in the Declaration of Helsinki and all the procedures and protocols were approved by the institutional review boards of the National Institute of Nutrition, Hyderabad, India and the University of Maryland, Baltimore, USA. Written informed consent was obtained from mothers of all participants.

\section{References}

1. Stevens GA, Finucane MM, De-Regil LM et al. Nutrition Impact Model Study Group (Anaemia) (2013) Global, regional, and national trends in haemoglobin concentration and prevalence of total and severe anaemia in children and pregnant and non-pregnant women for 1995-2011: a systematic analysis of population-representative data. Lancet Glob Health 1, e16-e25.

2. Stoltzfus RJ, Mullany L \& Black RE (2004) Iron deficiency anaemia. In Comparative Quantification of Health Risks: Global and Regional Burden of Disease Attributable to Selected Major Risk Factors, pp 163-210 [M Ezzati, AD Lopez, A Rodgers et al., editors]. Geneva: WHO.

3. Hadler MCCM, Juliano Y \& Sigulem DM (2002) Anaemia in infancy: etiology and prevalence. J Pediatr (Rio J) 78, 321-326.

4. Kotecha PV (2011) Nutritional anaemia in young children with focus on Asia and India. Indian J Community Med 36, 8-16.

5. Allen LH (2000) Anemia and iron deficiency: effects on pregnancy outcome. Am J Clin Nutr 71, 5 Suppl., 1280S-1284S.

6. Grantham-McGregor S \& Ani C (2001) A review of studies on the effect of iron deficiency on cognitive development in children. J Nutr 131, 6495-6685.

7. Algarin C, Peirano P, Garrido M et al. (2003) Iron deficiency anaemia in infancy: long-lasting effects on auditory and visual system functioning. Pediatr Res 53, 217-223.

8. Lozoff B, Jimenez E \& Smith JB (2006) Double burden of iron deficiency in infancy and low socio-economic status: a longitudinal analysis of cognitive test scores to 19 y. Arch Pediatr Adolesc Med 160, 1108-1113.

9. Iannotti LL, Tielsch JM, Black MM et al. (2006) Iron supplementation in early childhood: health benefits and risks. Am J Clin Nutr 84, 1261-1276.

10. Pasricha S, Drakesmith H \& Black J (2013) Control of iron deficiency in low- and middle-income countries. Blood 121, 2607-2617.

11. Sachdev HP \& Gera T (2013) Preventing childhood anaemia in India: iron supplementation and beyond. Eur J Clin Nutr 67, 475-480.

12. International Institute for Population Sciences \& ORC Macro (2007) National Family and Health Survey (NFHS-3), 2005-06, India: Key Findings. Mumbai: IIPS.

13. Pasricha S, Black J, Muthayya S et al. (2010) Determinants of anaemia among young children in rural India. Pediatrics 126, e140-e149.

14. Fernandez-Rao S, Hurley KM, Nair KM et al. (2014) Integrating nutrition and early child-development interventions among infants and preschoolers in rural India. Ann N Y Acad Sci 1308, 218-231.

15. International Institute for Population Sciences \& ORC Macro (2000) National Family and Health Survey (NFHS-2), 1998-99: India. Mumbai: IIPS.

16. Cogill B (2003) Anthropometric Indicators Measurement Guide, 2003 Revised Edition. Washington DC: Food and Nutrition Technical Assistance (FANTA) Project, FHI 360; available at http://www.fantaproject.org/sites/default/files/ resources/anthropometry-2003-ENG.pdf

17. World Health Organization (2007) The WHO Child Growth Standards, http://www.who.int/childgrowth/en/index.html (accessed March 2014).

18. Vazir S, Engle P, Balakrishna N et al. (2013) Clusterrandomized trial on complimentary and responsive feeding education to care-givers found improved dietary intake, growth and development among rural Indian toddlers. Matern Child Nutr 9, 99-117.

19. Coates J, Swindale A \& Bilinsky P (2007) Household Food Insecurity Access Scale (HFIAS) for measurement of Food Access: Indicator Guide, Version 3. Washington, DC: Food 
and Nutrition Technical Assistance (FANTA) Project, FHI 360; available at http://www.fantaproject.org/sites/default/ files/resources/HFIAS_ENG_v3_Aug07.pdf

20. International Nutritional Anaemia Consultative Group (1985) Measurement of Iron Status. A Report of the International Nutritional Anaemia Consultative Group (INACG), pp. 4-8. Washington, DC: The Nutrition Foundation.

21. Pawashe AB, Raman L, Nair KM et al. (1987) Validity of using capillary blood for the measurement of plasma ferritin. Clin Chim Acta 163, 119-120.

22. Perry DF (1990) Flame atomic absorption spectrometric determination of serum zinc; a collaborative study. $J$ Assoc Anal Chem 73, 619-621.

23. Siemens Medical Solutions Diagnostics (2012) Dual count solid phase no boil assay for vitamin $B_{12}$ and folic acid (brochure included with the kit). Los Angeles, CA: Siemens Medical Solutions Diagnostics.

24. International Zinc Nutrition Consultative Group (IZiNCG), Brown KH, Rivera JA et al. (2004) International Zinc Nutrition Consultative Group (IZiNCG) technical document \#1. Assessment of the risk of zinc deficiency in populations and options for its control. Food Nutr Bull 25, 1 Suppl. 2, S99-S203.

25. World Health Organization (2011) Hemoglobin Concentrations for the Diagnosis of Anaemia and Assessment of Severity. Vitamin and Mineral Nutrition Information System, WHO/NMH/NHD/MNM/11.1. Geneva: WHO.

26. World Health Organization (2011) Serum Ferritin Concentrations for the Assessment of Iron Status and Iron Deficiency in Populations. Vitamin and Mineral Nutrition Information System, WHO/NMH/NHD/MNM/11.2. Geneva: WHO.

27. Thurnham DI, McCabe LD, Haldar S et al. (2010) Adjusting plasma ferritin concentrations to remove the effects of subclinical inflammation in the assessment of iron deficiency: a meta-analysis. Am J Clin Nutr $92,546-555$.

28. Allen J, Backstrom KR, Cooper JA et al. (1998) Measurement of soluble transferrin receptor in serum of healthy adults. Clin Chem 44, 35-39.

29. Bharati S, Pal M, Chakrabarty S et al. (2011) Trends in socioeconomic and nutritional status of children younger than 6 years in India. Asia Pac J Public Health 23, 324-340.

30. Lutter CK (2008) Iron deficiency in young children in lowincome countries and new approaches for its prevention. J Nutr 138, 2523-2528.

31. Punnonen K, Irjala K \& Rajamäki A (1997) Serum transferrin receptor and its ratio to serum ferritin in the diagnosis of iron deficiency. Blood 89, 1052-1057.

32. Infusino I, Braga F, Dolci A et al. (2012) Soluble transferrin receptor (sTfR) and sTfR/log ferritin index for the diagnosis of iron-deficiency anemia. A meta-analysis. Am J Clin Pathol 138, 642-649.

33. Suominen P, Punnonen K, Rajamäki A et al. (1998) Serum transferrin receptor and transferrin receptor-ferritin index identify healthy subjects with subclinical iron deficits. Blood 92, 2934-2939.

34. Koulaozidis A, Said E, Cottier R et al. (2009) Soluble transferrin receptors and iron deficiency, a step beyond ferritin. A systematic review. J Gastrointest Liver Dis 18, 345-352.
35. Asobayire FS, Adou P, Davidson L et al. (2001) Prevalence of iron deficiency with and without concurrent anemia in population groups with high prevalence of malaria and infections: a study in Côte d'Ivoire. Am J Clin Nutr $\mathbf{7 4 ,}$ 776-782.

36. Ohlund I, Lind T, Hörnell A et al. (2008) Predictors of iron status in well-nourished 4-y-old children. Am J Clin Nutr 87, 839-845.

37. Bhutta ZA, Das JK, Rizvi A et al. Lancet Nutrition Interventions Review Group; Maternal and Child Nutrition Study Group (2013) Evidence-based interventions for improvement of maternal and child nutrition: what can be done and at what cost? Lancet 382, 452-477.

38. Armony-Sivan R, Kaplan-Estrin M, Jacobson SW et al. (2010) Iron-deficiency anaemia (IDA) in infancy and mother-infant interaction during feeding. J Dev Behav Pediatr 31, 326-332.

39. Paul VK, Sachdev HS, Mavalankar D et al. (2011) Reproductive health, and child health and nutrition in India: meeting the challenge. Lancet 377, 332-349.

40. Dean SV, Mason EM, Howson CP et al. (2013) Born too soon: care before and between pregnancy to prevent preterm births: from evidence to action. Reprod Health 10, Suppl. 1, S3

41. Mason JB, Shrimpton R, Saldanha LS et al. (2014) The first 500 days of life: policies to support maternal nutrition. Glob Health Action 7, 23623.

42. Ministry of Health and Family Welfare (2013) Guidelines for Control of Iron Deficiency Anaemia, National Iron + Initiative, Towards Infinite Potential in an Anaemia-Free India. New Delhi: Adolescent Division, Government of India.

43. De-Regil LM, Suchdev PS, Vist GE et al. (2013) Home fortification of foods with multiple micronutrient powders for health and nutrition in children under two years of age. Evid Based Child Health 8, 112-201.

44. Hentze MW, Muckenthaler MU, Galy B et al. (2010) Two to tango: regulation of mammalian iron metabolism. Cell $\mathbf{1 4 2}$, 24-38.

45. Eneroth H, Persson L, El Arifeen S et al. (2011) Infant anaemia is associated with infection, low birth weight and iron deficiency in rural Bangladesh. Acta Paediatr 100, 220-225.

46. Zhao A, Zhang Y, Peng Y et al. (2012) Prevalence of anaemia and its risk factors among children 6-36 months old in Burma. Am J Trop Med Hyg 87, 306-311.

47. Meinzen-Derr JK, Guerrero L, Altaye M et al. (2006) Risk of infant anaemia is associated with exclusive breast feeding and maternal anaemia in Mexican cohort. $J$ Nutr 136, 452-458.

48. Lozoff B, Kaciroti N \& Walter T (2006) Iron deficiency in infancy: applying a physiologic framework for prediction. Am J Clin Nutr 84, 1412-1421.

49. Yang W, Li X, Li Y et al. (2012) Anaemia, malnutrition and their correlations with socio-demographic characteristics and feeding practices among infants aged 0-18 months in rural areas of Shaanxi province in northwestern China: a cross-sectional study. BMC Public Health 12, 1127.

50. Leite MS, Cardoso AM, Coimbra CEA Jr et al. (2013) Prevalence of anaemia and associated factors among indigenous children in Brazil: results from the First National Survey of Indigenous People's Health and Nutrition. Nutr J 12, 69. 